\title{
A Structural Decomposition Analysis of the Pollution Terms of Trade
}

\author{
Christos T. Papadas* \& Nikolaos Vlassis** \\ *Agricultural University of Athens, Department of Agricultural Economics and Rural Development, Iera \\ Odos 75, Athens 118 55, Greece (cpap@aua.gr), +302105294724, corresponding author. \\ **University of Aberdeen, Business School, Department of Economics, Edward Wright Building s69, \\ Dunbar Street, Aberdeen AB24 3QY, Scotland, UK (nvlassis@abdn.ac.uk), +44(0)1224272178.
}

\begin{abstract}
The Antweiler Pollution Terms of Trade Index (PTTI) measures environmental gains or losses sustained by a country from international trade. Measuring total exports and imports in value terms distorts the results when the index is used for comparisons and analysis. Structural Decomposition Analysis (SDA) can provide an estimate of such distortions, due to price effects. This paper proposes a procedure of SDA of PTTI changes to deal with this problem. It measures impacts of changes in prices of traded outputs, changes in the real trade mix and volume, and changes in technology, but can be extended to account for other factors too. The pollution content refers here to pollution generated directly in the production of outputs, actually traded in the international markets. However, additional induced effects due to international trade can be included, if they are estimated. Pollution intensity is expressed per unit of total exports and imports respectively, and not per unit of value added, an issue discussed. A case study for The Netherlands is provided for the period 2007-2010. PTTI values and their annual changes are estimated for emission contents in greenhouse $\mathrm{CO}_{2}$ equivalent. Results confirm the significant and distortive role of prices in measurements and comparisons.
\end{abstract}

Keywords: Greenhouse emissions, Pollution content, Pollution terms of trade, Structural decomposition analysis.

JEL: Q50, Q55, Q56 


\section{Introduction}

Over the last 200 years, the world's population has grown roughly six times, world output has grown 60 times and world trade has grown over 140 times (WTO 2013, p 46). During the same time period, concentrations of GHG in the atmosphere increased approximately by $142 \%$ for $\mathrm{CO} 2$, $253 \%$ for methane and $121 \%$ for nitrous oxide (EPA Climate Change Indicators). This trade expansion and liberalization coupled with environmental concerns, environmental treaties, and country specific regulations, motivate theoretical research for the understanding of international trade impacts on the environment (Copeland and Taylor 2003). The need to test relevant theoretical views and to quantify countries' positions in the matrix of international trade -and- environmental pollution, lends weight to empirical approaches. Pollution embodied in exported and imported commodities change over time due to different trade mix, regimes, or due to technological change. It is thus important to measure the pollution content of tradeable goods and also its' changes over time. Indices based on such measurements are equally substantial. They summarize this information and facilitate its use.

Such indices consider one or more pollutants at a time. They may reflect absolute measurements such as the pollution content of exports, imports, and their difference, or they may reflect relative magnitudes such as the ratio of the pollution contents of exports and imports. Different indices are expected to capture different aspects of the relation between trade and environment, with their values depending on different variables. Changes in the indices reflect the impact of these variables. Knowledge of such changes and the significance of the specific forces that drives them is useful in interpreting environmental impacts due to trade, and evaluate different trade policy results on environmental pollution and its international distribution. 
In this study we focus on the Pollution Terms of Trade Index (PTTI) and its changes. PTTI is defined as the ratio of the pollution content per monetary unit of exports over the pollution content per monetary unit of imports. Structural Decomposition Analysis (SDA) methods based on information provided by Input-Output accounts, can be a particularly useful tool of analysis to estimate the contribution of different factors to these changes (Miller and Blair, 2009). A standard additive SDA method of PTTI changes is suggested. The role of volume and mix of trade, technological changes, and changes in prices of traded commodities can be captured while the method can be extended further to capture the role of more detailed factors and disaggregated results. Since the original PTTIs are expressed in monetary terms, comparisons of their values and changes, and certain decomposition analyses of them may yield results with serious distortions. We argue that differences in prices of the different traded commodities, as well as different changes in these prices, may significantly distort the measurement of the true pollution content of trade in the index and distort comparisons. The suggested SDA method is applied on data for The Netherlands. Compatible trade and environmental data are used and obtained from the Input Output tables and Environmental Accounts of the Dutch economy.

\section{Related Literature and Discussion}

The usefulness of Index Decomposition Analysis (IDA) and SDA methods on studying issues related to energy and emission of pollutants has been recognized since late 1970's ${ }^{1}$. IDA

\footnotetext{
${ }^{1}$ Ang and Zhang (2000) discuss developments and survey 117 IDA studies, up from 51 from a previous survey in 1995. A survey is also provided in Xu and Ang (2013). SDA reviews can be found in Rose and Casler (1996) and Miller and Blair (2009) as well. Hoekstra and van den Bergh (2002) discuss 27 SDA studies analyzing physical flows in the economy. Su and Ang (2012) discuss 43 SDA studies of the period 1999-2010, on energy and emissions, and classify them according to their different characteristics including their particular decomposition method.
} 
refers to decomposition analysis of index numbers or magnitudes expressed in terms of a base or previous year, and has been more popular in investigating energy use or emissions who are related to energy consumption. IDA is relatively less demanding in terms of data, and most often uses other than Input-Output (IO) table data. SDA methods on the other hand, usually rely heavily on information from such IO tables. The use of SDA methods was facilitated and expanded by the introduction of extended IO analysis, including energy and environmental IO models.

The evolution and advances in IDA applied in energy and emissions in particular, were examined in studies such as Ang et al. (2010, 2009, 2003). Developments in the use of SDA in energy and emissions and comparisons between IDA and SDA are provided and thoroughly discussed in Su and Ang (2012). Decomposition analyses can take both, additive or multiplicative forms. In the exact additive decomposition techniques, no residual term remains and the analyzed changes are perfectly attributed. Dietzenbacher and Los (1998) discuss alternative forms and uses of such methods found in past literature. They propose the use of the average of all exact decomposition forms or alternatively, the average of two polar techniques which was empirically found close to the overall average (concealing however as the authors argue the overall methodological differences). In the study of Su and Ang (2012) the authors construct and present the general mathematical framework of additive SDA methods which are exact and also ideal (i.e. the sequence of factors in the product to be analyzed does not affect the decomposition results), while an application on China's $\mathrm{CO}_{2}$ emissions is also presented.

Additive forms are the most common in SDA especially in studies on energy and pollution (Su and Ang, 2014, 2012) while the traditional multiplicative SDA cannot attribute changes to 
factors at the sectoral level ${ }^{2}$. In IDA, both multiplicative and additive forms are used (Ang et al., 2000, Su and Ang, 2014, 2012). Incorporating the attribution analysis in IDA suggested by Choi and Ang (2012), a multiplicative SDA method was developed by Su and Ang (2014). The method was introduced into the study of emissions embodied in trade, analyzing the contribution of the Chinese industrial sectors to the embodied $\mathrm{CO}_{2}$ emissions in the country's exports. Other multiplicative SDA studies in energy consumption include the work of Fan and Xia (2012) and Zhang and Lahr (2014). Further contributions in the introduction of multiplicative SDA in energy and emissions are found in Su and Ang (2015) ${ }^{3}$.

Several studies, starting with Proops et al. (1993), applied spatial rather than temporal decomposition analysis on energy and emissions. Recent substantial contributions at the theoretical level as well, can be found in Su and Ang (2016) and Ang et al. (2015). In Ang et al. (2015) alternative approaches to spatial IDA are discussed and compared. A framework for interregional energy efficiency comparisons using IDA is also provided. In Su and Ang (2016) a framework for multiregional SDA is presented and four extended Leontief models for spatial SDA of both, additive and multiplicative forms are constructed.

\footnotetext{
${ }^{2}$ A multiplicative SDA method was proposed by Dietzenbacher and Los (1998), and has been adopted in several studies. In Su and Ang (2014) it is shown that this method is conceptually similar to the generalized Fisher index method in IDA (Ang et al., 2004).

${ }^{3}$ In Su and Ang (2015) four alternative Input-Output models are introduced to study an economy's aggregate carbon intensity and an application in the study of China's intensity is provided. The different models are distinguished by different combinations of 10 analyses, imports assumptions and GDP calculation. The alternative way of treating imports (competitive versus non-competitive) which is in general particularly significant in the construction of 10 tables and analysis, is addressed by the authors for the Leontief and also for the Ghosh models. A formal analysis of the two treatments of imports and their consequences is provided, as is also the case in Su and Ang (2013).
} 


\section{The Pollution Terms of Trade Index}

The concept and index of the pollution terms of trade (PTT) was introduced by Antweiler (1996) in order to measure a country's environmental gains and losses caused by international trade. Another measure suggested by Muradian et al., (2002) was the use of the balance of emissions embodied in trade, i.e. the difference between pollution embodied in exports and in imports. The latter found several applications in the literature and without doubt provided valuable information on the overall pollution effect of international trade activities. Nevertheless, the measure is affected by the size of the international trade balance and its short term changes, and its stability for long run analysis is reduced (Antweiler, 1996, Strauman, 2003). As in the case with the international terms of trade, there is also a need for an equivalent index with respect to pollution, which is unaffected by the size of trade balance. Such an index would also capture a long term view. The Antweiler PTTI satisfies the aforementioned criteria as a measure of relative trade weighted pollution intensity. It is defined as the ratio of pollution embodied per monetary unit of exports over the pollution embodied per monetary unit of imports, where pollution refers to anyone or more particular pollutants.

Previous efforts to construct a pollution terms of trade index were based on pollution abatement costs (Kalt 1988, Robinson 1988). The idea was inspired by Walter (1983) who suggested the use of the abatement-cost content of trade but did not produce a theoretically justified measure. Moreover, as Antweiler (1996) maintains these efforts did not lead to the construction of indices appropriate for international comparisons. Based on Antweiler's Pollution Terms of Trade Index (PTTI), a country "gains" from trade in environmental terms when the exported goods have a lower pollution content per monetary unit, than the corresponding content of imports. In such a 
case the value of the index is lower than one. If a country engages in "environmental dumping" it aims at a reduction of the PTTI.

Consider $\mathrm{n}$ traded commodities $(\mathrm{i}=1,2, \ldots, \mathrm{n})$ for a country trading with $\kappa$ other countries $(\mathrm{j}=1,2, \ldots, \kappa), \Theta$ pollutants $(\theta=1,2 \ldots, \Theta)$ produced in the production processes of the $\mathrm{n}$ outputs, and $\psi_{\theta \mathrm{ij}}$ is the content of $\theta$ per unit of produced $\mathrm{i}$ in country $\mathrm{j}$, then the PTTI of a certain country and period $t$ can be written using summations rather than matrix forms, as:

$$
(\text { PTTI })_{t}=\frac{\left(\sum_{i=1}^{n} X_{i t}\right)^{-1} \sum_{\theta=1}^{\Theta} \sum_{i=1}^{n} \omega_{\theta} \psi_{\theta i t} \mathrm{X}_{i t}}{\left(\sum_{i=1}^{n} \sum_{j=1}^{\kappa} \mathrm{M}_{i j t}\right)^{-1} \sum_{\theta=1}^{\Theta} \sum_{i=1}^{n} \sum_{j=1}^{\kappa} \omega_{\theta} \psi_{\theta i j t} \mathrm{M}_{i j t}}
$$

where $X_{i}$ is the value of $\mathrm{i}$ exported from the country and $M_{i j}$ is the value of $\mathrm{i}$ imported from country $\mathrm{j}$. Moreover, $\omega_{\theta}$ is a weight corresponding to the particular pollutant $\theta$. Weights make comparable different pollutants possibly measured in different units, or assign a different degree of significance to each pollutant, or both. Based on their definition, coefficients $\psi_{\theta i j}$ represent different production technologies with respect to each pollutant $\theta$ in the production process of each output $\mathrm{i}$, in each country $\mathrm{j}$.

Antweiler (1996) provided estimates for 164 countries which reflected two influential factors. One is the composition effect that depends on the mix and quantities of exported and imported commodities. The second is the technology effect that is related to the production process of each traded commodity in each country. Lack of detailed data in Antweiler's study led to the assumption that technologies for the same commodities are similar across trading countries, i.e. 
the pollution content of a traded commodity per unit is the same regardless of the country of production. As a result, when this common assumption is made, differences in PTTI values reflect only different composition effects.

Grether and Mathys (2013) propose the use of a revised PTTI differing from the original in that pollution contents of exports and imports are calculated per unit of value added rather than total value of exports and imports respectively (Johnson and Noguera, 2012) ${ }^{4}$. Their calculation of the revised PTTI includes final demand driven, domestically induced effects, due to bilateral trade relationships. Emission contents of domestically traded outputs, due to intermediate transactions initiated by international trade at the bilateral level, are thus included in the calculation of the revised PTTI. Estimation of such outputs are based on the use of final demand driven input-output multipliers. The study of Grether and Mathys (2013) refers to embodied $\mathrm{SO}_{2}$ emissions and provides a multiplicative factor decomposition analysis (FDA) method of the revised PTTI ${ }^{5}$. For each year and country, the corresponding PTTI values are broken down into between-sector effect, between-country effect, and effects of technology, intermediate trade and value added.

The inclusion in PTTI of emission contents in output traded domestically and generated by induced effects of international trade, is an attempt to estimate and capture what is considered the "true pollution or emission content generated by trade". It is an extension and application of the

\footnotetext{
${ }^{4}$ In Johnson and Noguera (2012) the value added content of trade is measured to avoid the problem of double counting in the value of trade when there is increased world-wide production sharing.

${ }^{5}$ The authors considered $\mathrm{SO}_{2}$ emissions for 62 developing and developed countries over the 1990-2000 period. They account for different technologies of production in similar sectors of different countries resulting in different emission intensities. They use input output tables for the countries of the study where in final demand, international trade of every country is broken down to bilateral trade with all other countries separately.
} 
discussion on the "true factor content of trade". The original Vanek concept of factor content of trade and predictions based on that, face trouble when the assumption of similar production technologies is lifted and international trade in production inputs is present. Trefler and Zhu (2010) proposed an algorithm giving Vanek-consistent predictions. They took under consideration that models satisfying Vanek predictions are more than the Heckscher-Ohlin consistent models. They also adopted as correct Vanek-relevant definition of the factor content of trade, the one suggested by Deardoff (1985). The algorithm uses Input-Output (IO) table data on trading countries to capture the factor content of trade.

More recently Duan and Jiang (2017) presented an SDA method to analyze changes in the revised by Grether and Mathys (2013) PTTI of China, with $\mathrm{CO}_{2}$ emissions embodied in exports and imports, measured per unit of value added. The authors cover the period 1995-2009 and they use the World Input-Output Database (WIOD) with the economies of 40 countries classified in 35 sectors. There is also a similar aggregate table for the rest of the world. Duan and Jiang (2017) also attempted to capture the content of emissions due to induced effects of bilateral international trade. They do so in a more complete way because in addition to data on bilateral trade as final demand transactions, their multiregional Input-Output (MRIO) model accounts for bilateral intermediate sectoral transactions between countries as well. Their SDA approach allows for the measurement of the technology effect, composition of final demand effect, final trade effect, and intermediate trade effect, on changes of the revised PTTI.

We suggest here an additive SDA method to examine changes in the original Antweiler PTTI. The SDA method proposed and applied by Duan and Jiang (2017) on the revised PTTI is multiplicative. Additive forms have prevailed in SDA even though multiplicative forms gain popularity and are considered more suitable for intensity or index changes. Still however, additive 
SDAs are usually preferred in the analysis of absolute quantity changes and we use the additive form here to analyze absolute changes in the value of the original PTTI. Calculating and using the pollution embodied in exports and imports adding all effects induced by international trade is understandable, if the researcher wishes to associate the overall pollution generation with international trade activity between trading regions. Nevertheless, we consider the pollution content of commodities actually traded in the international market, valuable information as such. Similarly, it is a useful task to measure and analyse the PTTI based on this information, as in Antweiler (1996). This is the reason also, that this type of "direct" pollution content has been used often in decomposition analysis of the pollution content of the volume of trade, at its levels. Even though this is our approach here, our standard additive SDA technique can easily be applied on the PTTI using also the pollution content of induced output effects, once the latter is estimated.

Similar comments apply on the measurement of pollution content per unit of value added which also aligns with the energy and emissions intensities set by the countries. As Duan and Jian (2017) who used the revised PTTI argue, this is “more appropriate when reflecting a country's environmental cost compared to its economic gains". In our study we measured pollution contents per unit of total exports and total imports as originally proposed by Antweiler (1996), since we were more interested in the comparison of such pollution intensities between exports and imports in order to compare environmental costs and benefits. If one is interested in comparing purely environmental gains and losses due to trade, and test in this spirit hypotheses such as "environmental dumping", we believe this approach to PTTI is more appropriate.

A problem with the use of the original PTTI lies in the fact that the denominators of both the nominator and denominator in (1), i.e. total exports and total imports respectively, are expressed in monetary values. This biases the results when comparisons are made as in Antweiler (1996). 
Differences in the trade mix over countries or time, combined with the different international prices of the different commodities, do not allow reliable comparisons of PTTI values. Resorting to actual commodities instead of their monetary values, would have made their aggregation impossible. The problem persists of course when induced effects are considered in the index.

As a result, when the original PTTI rather than the revised one is more appropriate, the problem appears also in decomposition analysis, where values of the original PTTI at their levels are attributed to factors affecting their value (eg. factor decomposition analysis) or regression analysis is performed.

Unlike comparisons of PTTIs at their levels across regions and years, in SDA of PTTI changes the problem can be avoided, if data used are expressed in constant prices (as in Duan and Jiang (2017) for the revised PTTI). This way, the PTTI changes can be estimated without the impact of prices and their changes. They would provide therefore changes in the true environmental gains and losses.

Changes in the PTTI are not less important than the values of the index at its levels. Even without the distorting effect of prices, estimated values of PTTI at a given time may not necessarily reflect environmental impacts of policies, incentives, regimes, etc. They may simply reflect existing comparative advantages and technologies.

It is of interest and useful therefore to examine changes in the Antweiler PTTI values over time, as policies and institutional or legal frameworks change. The distortion to results of SDA if the impact of prices is not subtracted in intertemporal analysis, can provide an estimate of their distorting role when original PTTIs are used at their levels too. For this reason, together with the suggestion of an additive SDA technique of changes in the values of the Antweiler index in (1), it is our purpose to use this technique to capture the impact of prices on PPTI estimates using current 
data. As before, we should make clear that if SDA of the original PTTI using IO data in constant prices is the objective, then the suggested additive technique is easily modified to capture other impacts (including and beyond the non-price effects of this paper).

The availability of IO tables in constant prices allows for the construction of price indices for traded commodities, and the separate calculation of impacts caused by actual traded quantities and prices, on changes of the PTTI in (1). Price indices are constructed for the value of domestic production by economic sector, imports, and exports, classified per similar foreign or domestic sectors respectively. The technique presented here estimates the role and significance of: (a) changes in prices of exported and imported commodities, (b) real changes in the mix and magnitude of traded quantities that have pollution content, and (c) changes in production technologies of the different traded commodities, but could take into account more factors.

As a case study the technique is applied on the year to year changes of the PTTI using Eurostat's data on The Netherlands for the period 2007-2010. The Dutch environmental accounts for the same four years were combined with Input-Output accounts for the Dutch economy in current and previous year prices. The Antweiler PTTI is calculated with respect to the three greenhouse gas pollutants, expressed and treated as one pollutant in terms of greenhouse $\mathrm{CO}_{2}$ equivalent. Different or more pollutants can be considered simultaneously as in (1).

\section{Data and Methodology}

The set of 2007-2010 Input-Output tables published by Eurostat includes the Use and Supply Matrices and the derived "Symmetric" Input-Output Tables ("Siot") which are of the traditional sector by sector Leontief form. Unlike most of the European Siot matrices which are of the commodity by commodity Leontief form, the sector by sector form makes the Dutch Siot tables most suitable for use in combination with the environmental accounts which provide pollution data 
on a sectoral basis, (even though under certain assumptions such Siot matrices can be constructed separately for other countries too).

All Dutch tables are given in current and previous year prices which allows for the construction of price indices for each sector by sector and final demand transaction. This can be done also for the overall sectoral outputs, exports, and imports. Every change in values can be broken down to changes due to actual quantities and prices. Moreover, the Siot tables are given broken down in two detailed matrices one of which refers to domestic transactions with domestically produced outputs and another one with imported outputs. The sum of the two matrices is the original Siot. As with the latter, the two matrices are given for the $2007-2010$ period in both, current and previous year prices.

Information provided by the Central Bureau of Statistics of the Netherlands and Eurostat on greenhouse gasses (carbon dioxide $\mathrm{CO}_{2}$, methane $\mathrm{CH}_{4}$, and nitrous oxide $\mathrm{N}_{2} \mathrm{O}$ ) were also utilized. We used in particular the data on greenhouse $\mathrm{CO}_{2}$ gas equivalent which was treated as one pollutant. The latter is a weighted sum of the three greenhouse gasses. The Antweiler PTTI with respect to greenhouse $\mathrm{CO}_{2}$ gas equivalents is used in our SDA in its initial form and under altered assumptions. The environmental accounts provide information on emissions of the greenhouse gas equivalents and other pollutants on a sector by sector basis for a series of years including the 20072010 period. Sectors are defined in a similar way as in the IO Tables according to NACE 2. The tables classify the economy into sixty-five domestic, producing, endogenous (i.e. non final demand) sectors, two of which however have no economic activity and there are no imports of corresponding foreign sectors. Some of the NACE 2 sectors of the environmental accounts are in a more disaggregated and others in a more aggregated form than the sectors in the IO Tables. 
To achieve exact correspondence, we aggregated and classified all economic sectors into thirty-nine and calculated their total domestic output and exports, together with imports of corresponding foreign outputs. This corresponds to data treatment I in Su et. al (2010) as opposed to treatment II where data on energy consumption or emissions are disaggregated, directly if possible or extrapolating information, to match IO sectors ${ }^{6}$. It was done using the Leontief Siot tables in both, current and previous year prices. For each year $t$ and each sector $i$ the greenhouse gas equivalent per unit of output $\psi_{\mathrm{it}}$ (in ton. per mil. euros) was estimated using the sectoral outputs in current prices. Multiplying each coefficient by the corresponding sectoral exports we have the pollution content of these sectoral exports and their sum gives us the pollution content of all exports.

In Antweiler (1996), lack of detailed or accurate data led to the assumption that for the same sectoral outputs similar technologies of production with respect to greenhouse emissions prevail in both, the Dutch sectors and in the other trading countries. That means that for output $i$ the same $\psi_{\text {it }}$ prevail in all countries. This assumption certainly biases the results but we have adopted it in our case study as well. As in the case of exports, using these coefficients we can find the pollution content of each imported $i$ and the pollution content of total imports. If different technologies and emission coefficients $\psi_{\text {it }}$ prevail and data are available, nothing changes in the suggested method of SDA.

\footnotetext{
${ }^{6}$ In Su et. al (2010) a formal presentation and analysis of the two approaches is presented together with distorting results due to assumption or lack of accurate data. Moreover, the impact of sector aggregation on estimated emissions embodied in China's exports, is investigated.
} 
Using superscripts $\mathrm{cp}$ and $\mathrm{pp}$ to denote values of exports and imports in current and previous year prices respectively ( $\psi_{\mathrm{it}}$ 's are always here in current prices), we define the Antweiler PTTI for year $t$ in current prices as:

$$
(P T T T)_{t}^{c p}=\frac{\left(\sum_{i=1}^{n} X_{i t}^{c p}\right)^{-1} \sum_{i=1}^{n} \psi_{i t} X_{i t}^{c p}}{\left(\sum_{i=1}^{n} \sum_{j=1}^{K} \mathrm{M}_{i j t}^{c p}\right)^{-1} \sum_{i=1}^{n} \sum_{j=1}^{k} \psi_{i t} M_{i j t}^{c p}}
$$

We define similarly the index for year $\mathrm{t}$, measured in previous year (t-1) prices as:

$$
(P T T I)_{t}^{p p}=\frac{\left(\sum_{i=1}^{n} X_{i t}^{p p}\right)^{-1} \sum_{i=1}^{n} \psi_{i t} X_{i t}^{p p}}{\left(\sum_{i=1}^{n} \sum_{j=1}^{K} \mathrm{M}_{i j t}^{p p}\right)^{-1} \sum_{i=1}^{n} \sum_{j=1}^{k} \psi_{i t} M_{i j t}^{p p}}
$$

We define now the index for year $t$ in current prices (or previous year prices), that would have prevailed under the technology of the previous year (t-1), using the star symbol * as:

$$
(P T T I)_{t^{*}}^{c p(p p)}=\frac{\left(\sum_{i=1}^{n} X_{i t}^{c p(p p)}\right)^{-1} \sum_{i=1}^{n} \psi_{i(t-1)} X_{i t}^{c p(p p)}}{\left(\sum_{i=1}^{n} \sum_{j=1}^{K} \mathrm{M}_{i j t}^{c p(p p)}\right)^{-1} \sum_{i=1}^{n} \sum_{j=1}^{k} \psi_{i(t-1)} M_{i j t}^{c p(p p)}}
$$


Based on the above definitions and concepts, the total change of the defined and measured Antweiler PTTI between two periods t-1 and t, is given by $(P T T)_{t}^{c p}-(P T T I)_{t-1}^{c p}(5)$. The change in (5) can be broken down, initially into two parts: A part is caused solely by changes in prices of traded commodities, given by $(P T T I)_{t}^{c p}-(P T T I)_{t}^{p p}$ (6). Another part is caused by changes in both, the real volume and mix of trade, and technology with respect to pollutant emissions ( $\psi$ 's). It equals $(P T T)_{t}^{p p}-(P T T)_{t-1}^{c p}$ (7). The change in (5) can be broken down also in the following two parts: One is the change in real volume and mix of trade, which is equal to $(\text { PTTI })_{t^{*}}^{p p}-(\text { PTTI })_{t-1}^{c p}$ (8). The other is the change in both, technology ( $\left.\psi^{\prime} s\right)$ and prices, given by $(P T T)_{t}^{c p}-(P T T I)_{t^{*}}^{p p}(9)$. The part of change in (5) due to changes in technology only, is given by the difference $(P T T)_{t}^{p p}-(P T T)_{t^{*}}^{p p}(10)$. As expected, using the concepts, (10) should be derived also as the difference (9) minus (6), or the total change in (5) minus the sum of (6) plus (8). Other equations resulting from the concepts exist and can be used to confirm the formulas measuring the role of one or two of the three factors examined, in causing the total change (for example the change due to real volume and mix of trade in (8) equals the total change in (5) minus the change due to changes in technology and prices (9)).

What is of essence here, is the fact that the total change of the Antweiler PTTI between t-1 and $t$, as expressed in (5) can be divided into three parts: The difference in (6) caused by changes in prices, the difference in (8) caused by changes in the real volume and mix of trade, and the difference in (10) caused by changes in technology with regards to pollution content per unit of exported and imported commodities. This type of SDA can be conducted for any length of period 
instead from year to year. However, trade data in previous year prices should be expressed then in prices of any other original period.

Expressions (5), (6), (8), and (10) give us the value of change in the Antweiler index and its decomposition into the three parts. If for every year $t$ we divide the results of all these expressions by $(P T T I)_{t-1}^{c p}$ we obtain the percentage change of the index and the part of this percentage change attributed to prices, the real volume and mix of trade, and technology. As expected the sum of the three parts equals the percentage change of the index. Moreover, dividing every difference in (6), (8), and (10) by (5), we obtain the percentage share of the change in index, that can be attributed to prices, real volume and mix of trade, and technology. The sum of the last three percentages equals of course unity.

\section{Results}

Using the mentioned data and variables for The Netherlands for the years 2007-2010 and the interim year to year periods as a case study of the proposed SDA for the Antweiler PTTI in (1) which was estimated for each year. The magnitudes in (2), (3) and (4) were also estimated. Subsequently we estimated the change in PTTI as is (5) and the changes in (6), (8), and (10). The results for all changes are given below in Table 1.

Table 1: Changes in the Antweiler PTTI and the impacts of the three factors

\begin{tabular}{|l|l|l|l|l|l|l|}
\hline Year & $(\text { PTTI })^{\mathrm{cp}}$ & $(\text { PTTI })^{\mathrm{pp}}$ & Total change & Price effect & Trade effect & Technology effect \\
\hline & & & $(P T T I)_{t}^{c p}-(P T T I)_{t-1}^{c p}$ & $(\text { PTTI })_{t}^{c p}-(P T T I)_{t}^{p p}$ & $(P T T I)_{t^{*}}^{p p}-(P T T I)_{t-1}^{c p}$ & $(\text { PTTI })_{t}^{p p}-(P T T I)_{t^{*}}^{p p}$ \\
& & & & & & \\
\hline 2010 & 1.218 & 1.222 & -0.171 & -0.004 & -0.172 & 0.005 \\
\hline 2009 & 1.389 & 1.259 & 0.163 & 0.130 & 0.036 & -0.002 \\
\hline 2008 & 1.226 & 1.252 & -0.016 & -0.026 & 0.012 & -0.001 \\
\hline 2007 & 1.241 & & & & & \\
\hline
\end{tabular}


The results are quite interesting because despite the short overall period covered, we can see cases of relatively small and large changes in the observed PTTIs and a diverse behavior in the role of the factors influencing their changes. Moreover, as one would expect, the change in the PTTIs caused by changes in technology are small in absolute magnitude for year to year periods. However, these changes still provide interesting information on the SDA of the index.

During the first period 2007-2008 the Antweiler PTTI undergoes an insignificant change of negative sign. This is due to the price effect, with the sum of the two other effects having a positive sign. The results serve to show that although the measured index declines, if we had measured the content of pollution per actual quantity unit of traded commodities the result would have been of the opposite sign. If we are interested in actual pollution content therefore and the consequences of trade and environmental policy such as environmental taxes, dumping, etc. it is the change in the sum of technology effect and the real volume and trade effect that we should be looking at, with the distinction between the two effects being done to evaluate the role of technology change and possibly for other purposes related to technology.

During the second period the index presents a much larger and rather significant change. A look however at the results for the period shows that this impression is largely created by changes in prices of the traded commodities. The sum of the other two effects is very small. Unlike the observed magnitude of change in PTTI, if the change in actual pollution content of trade was taken under consideration only, the pollution terms of trade would present a much smaller change. In the third period 2009-2010 the measured Antweiler PTTI displays a reduction in which the role of prices change played now a minimal role. The real trade effect seems to be the most important factor for the outcome this time and the reduction of the index reflects to a large extent changes in 
the actual pollution content of trade. This is always given by the sum of the two non-price effects as in (7).

The significance of each factor for the changes of the index appears clearer in the two tables that follow. In both tables the three first columns are the same as in Table 1, referring to the values of the index in current and previous year prices for each year.

Table 2: Percentage change of the Antweiler PTTI, and its' parts of the three factors.

\begin{tabular}{|l|l|l|l|l|l|l|}
\hline Year & (PTTI $^{c p}$ & $(\text { PTTI })^{\text {pp }}$ & Total \% change & Price effect & Trade effect & Technology effect \\
\hline & & & $\frac{(P T T I)_{t}^{c p}-(P T T I)_{t-1}^{c p}}{(P T T I)_{t-1}^{c p}}$ & $\frac{(P T T I)_{t}^{c p}-(P T T I)_{t}^{p p}}{(P T T I)_{t-1}^{c p}}$ & $\frac{(P T T I)_{t^{*}}^{p p}-(P T T I)_{t-1}^{c p}}{(P T T I)_{t-1}^{c p}}$ & $\frac{(P T T I)_{t}^{p p}-(P T T I)_{t^{*}}^{p p}}{(P T T I)_{t-1}^{c p}}$ \\
\hline 2010 & 1.218 & 1.222 & -0.123 & -0.003 & -0.124 & 0.004 \\
\hline 2009 & 1.389 & 1.259 & 0.133 & 0.106 & 0.029 & -0.002 \\
\hline 2008 & 1.226 & 1.252 & -0.013 & -0.021 & 0.010 & -0.001 \\
\hline 2007 & 1.241 & & & & & \\
\hline
\end{tabular}

The fourth column of Table 2 provides the three sequential percentage changes of the index for the covered period. This column is also the sum of the three last columns that follow. These columns present separately the parts of the total percentage change in PTTI, attributed to the three effects. The impact of the three factors in terms of the relative changes in PTTI they cause, becomes clear. The small percentage change of $-1.3 \%$ between the first two years is mostly due to the price effect, which caused a $-2.1 \%$ change in the index and determined also the sign of its change. The sum of the two other effects causes an almost $1 \%$ positive change in the index. The relatively large percentage increase of the index (13.3\%) during the next one-year period, is attributed again to the role of prices which caused a $10.6 \%$ percent change in the index. The change in actual pollution content of trade due to real volume and trade mix changes and technology changes as well, is very small in relative terms. Another possibility and completely different 
situation appears during the third one-year period. The $-12.3 \%$ change of the index can be attributed now almost solely to the two non-price effects which cause a $12 \%$ change in the value of the Antweiler PTTI.

Table 3 that follows is perhaps more informative and shows the relative importance of each factor in terms of its relative share of effect in the total change of the Antweiler PTTI, regardless of what its' absolute or percentage change is in the specific period.

Table 3: Percentage change and percentage shares of the total Antweiler PTTI change.

\begin{tabular}{|l|l|l|l|l|l|l|}
\hline Year & $(\mathrm{PTTI})^{\mathrm{cp}}$ & $(\mathrm{PTTI})^{\mathrm{pp}}$ & Total \% change & Price effect & Trade effect & Technology effect \\
\hline & & & $\frac{(P T T I)_{t}^{c p}-(P T T I)_{t-1}^{c p}}{(P T T I)_{t-1}^{c p}}$ & $\frac{(P T T I)_{t}^{c p}-(P T T I)_{t}^{p p}}{(P T T I)_{t}^{c p}-(P T T I)_{t-1}^{c p}}$ & $\frac{(P T T I)_{t^{*}}^{p p}-(P T T I)_{t-1}^{c p}}{(P T T I)_{t}^{c p}-(P T T I)_{t-1}^{c p}}$ & $\frac{(P T T I)_{t}^{p p}-(P T T I)_{t^{*}}^{p p}}{(P T T I)_{t}^{c p}-(P T T I)_{t-1}^{c p}}$ \\
\hline 2010 & 1.218 & 1.222 & -0.123 & -0.026 & -1.005 & -0.030 \\
\hline 2009 & 1.389 & 1.259 & 0.133 & 0.798 & 0.220 & -0.017 \\
\hline 2008 & 1.226 & 1.252 & -0.013 & 1.696 & -0.785 & 0.089 \\
\hline 2007 & 1.241 & & & & & \\
\hline
\end{tabular}

The first three columns are the same as in the previous tables while the fourth is the same as in Table 2 showing the percentage change of the index. The three columns that follow show the size of each effect as a share of the change in index, i.e. the relative shares, which as expected sum up to unity. It should be noted that their signs are not always the same as their corresponding estimates in the other tables above. A positive sign for an effect now implies that the sign and direction of the effect's influence on the index is the same as the direction of overall change of the index.

During the first one-year period the price effect is $169.6 \%$ of the total change in the index showing again the significance of the price changes which imposed the negative sign of the index's 
change. The two non-price effects showing the impact of changes in the true pollution content of trade have a negative share of $69.6 \%$ of the total change in the PTTI indication. Their total effect is in the opposite direction than the one that prevailed over the index. It is interesting that when shares of impacts are considered which diminish -to some extent only- the influence of the small size of the periods examined on the measured technology effect, the latter becomes clearer. For this particular one-year period, almost $9 \%$ of the total PTTI change is caused by technology changes which considered separately from the other non-price effect, cause a change of the index towards its actual direction of change.

During the second period a large share of almost $80 \%$ of the change in the index, can be attributed to changes in prices of the traded commodities. This adds to a positive $22 \%$ share of the real trade effect. A small negative share corresponds to the technology effect showing now that this effects tends to move the index towards the opposite to its prevailing direction. Here the price changes are seen again as expected from previous results, as the major factor driving the change in the index value with the two non-price effect playing a relatively smaller role. A different situation arose as known in the third period and appears here. The share of real trade effect tells the whole story with the share of price effect being very small. Both effects reinforce each other and they are positive since they both contribute to the prevailing reduction of the index. A negative share of $3 \%$ belongs to the technology effect showing that its size is a small share of the total change in index and moved the index towards the opposite than the prevailing direction.

\section{Final remarks}

We discussed the issue of the original Antweiler Pollution Terms of Trade Index (PTTI) and its values. Given the objectives of research we argue that its use may be more suitable than the revised PTTI using value added. The latter is preferred if one wishes to account for economic 
gains/losses compared to environmental gains/losses due to international trade. When other hypotheses are examined (eg. environmental dumping as such), we believe the original Antweiler PTTI is preferred, either with induced effects or not. However, price effects distort the use of the original index for intertemporal and intercountry comparisons and conclusions. SDA analysis can show the impact of prices if one is interested. The problem persists if factor component analysis is conducted at the levels of the index, due to lack of appropriate price data.

Due to this distortion, intertemporal SDA on changes of the index can better reflect the impact of regulation, taxation, or incentives on the relative pollution content of trade per unit of traded commodities. We proposed a technique of standard additive SDA of changes in the index. The method measures the impact of changes in prices of traded commodities, the impact of changes in the mix and actual volume of trade, and the impact of changes in technology of production in terms of pollutant generation per unit of production. The impact of changes in the real volume and mix of trade and technology of production are what we should consider as changes in the index due to actual changes in the pollution content of trade.

We used emissions of the $\mathrm{CO}_{2}$ greenhouse equivalent in our study for the Netherlands, but another or more pollutants can also be used in applying the proposed SDA method. In addition, lack of data forced us to assume that technology of production of each specific traded commodity has been similar in the producing countries. This restrictive assumption found also in the literature, can be lifted if data are available without any changes in the logic and basics of the SDA method. Trying to lift the assumption in our empirical analysis using intercountry IO tables and other data and methods found in the literature, resulted in the necessity to make various assumptions for the missing data (as in this literature) which we consider also restrictive. More importantly, the lack 
of certain data in these datasets hindered our ability to account for effects of price changes that we consider very important.

Appropriate use of the index should be based on its' definition and the subject of research. On the other hand, previous empirical results using the index, may seem "paradoxical" because there is no separate consideration of prices and not because the initial PTTI's definition is irrelevant to the tested theories.

We showed using the Dutch IO and environmental accounts on greenhouse $\mathrm{CO}_{2}$ gas equivalents how changes in prices can reverse, minimize, and substantially magnify the value of measured PTTI changes and values. Hence, subtracting the effect of price changes can considerably change the conclusion of a hypothesis testing. What matters for practical purposes is that the changes in the actual pollution content of trade is considered when the redistribution of environment-polluting activities is examined. The SDA additive technique can be used also with IO data expressed in constant prices, (i.e. with the results unaffected by price distortions) to attribute PTTI changes to the same as here, or more real factors. Our additive method is exact and all PTTI changes are attributed to examined factors, with no residual term due factor interaction. However, as is the case with SDA techniques, the interaction of factors and the influence of one on the significance of the other is not captured.

\section{Bibliography}

Ang, B. W., Zhang, F.Q. (2000) A survey of index decomposition analysis in energy and environmental studies. Energy 25 (12), 1149-1176.

Ang, B. W., Liu, F. L., Chew, E. P. (2003). Perfect decomposition techniques in energy and environmental analysis. Energy Policy 31 (14), 1561-1566. 
Ang, B. W., Liu, F. L., Chung, H. S. (2004) A generalized Fisher index approach to energy decomposition analysis, Energy Economics, 26(5), 757-763.

Ang, B. W., Huang, H. C., Mu, A. R. (2009) Properties and linkages of some index decomposition analysis methods. Energy Policy 37 (11), 4624-4632.

Ang, B. W., Mu, A. R., Zhou, P. (2010) Accounting frameworks for tracking energy efficiency trends. Energy Economics 32 (5), 1209-1219.

Ang, B. W., Xu, X. Y., Su, B. (2015) Multi-country comparisons of energy performance: the index decomposition analysis approach. Energy Economics, 47, 68-76.

Antweiler, W. (1996) The pollution terms of trade. Economic Systems Research 8 (4): 361-365.

Choi, K. H., Ang, B. W. (2012) Attribution of changes in Divisia real energy intensity index: an extension to index decomposition analysis. Energy Economics 34 (1), 171-176.

Copeland, B. R., Taylor, M. S. (2003) Trade and the Environment: Theory and Evidence. Princeton University Press.

Deardoff, A. V. (1982) The general validity of the Heckscher-Ohlin Theorem. American Economic Review 72 (4), 683-694.

Dietzenbacher, E., Los, B. (1998) Structural decomposition techniques: sense and sensitivity. Economic Systems Research 10 (4), 307-323.

Duan, Y., Jiang, X. (2017) Temporal change of China's pollution terms of trade and its determinants. Ecological Economics 132, 31-44.

EPA (2013) Climate Change Indicators: Atmospheric Concentrations of Greenhouse Gases.

Fan, Y., Xia, Y. (2012) Exploring energy consumption and demand in China. Energy 40, 23-30.

Grether, J-M., Mathys, N. A. (2013) The pollution terms of trade and its five components. Journal of Development Economics 100, 19-31. 
Hoekstra, R., van den Bergh, J. C. J. M. (2002) Structural decomposition analysis of physical flows in the economy. Environmental and Resource Economics 23 (3), 357-378.

Johnson, R. C., Noguera, G. (2012) Accounting for intermediates: production sharing and trade in value added. Journal of International Economics 86 (2), 224-236.

Kalt, J. P. (1988) The impact of domestic environmental regulatory policies on US international competitiveness. In: A. M. Spence, H. A. Hazard (eds) International Competitiveness. Cambridge, MA, Ballinger, 221-262.

Miller, R. E., Blair, P. D. (2009) Input-Output Analysis: Foundations and Extensions. Cambridge University Press.

Muradian, R., O'Connor, Martinez-Alier, J. (2002) Embodied pollution in trade: estimating the "environmental load displacement" of industrialized countries. Ecological Economics 41, 51-67.

Proops, J., Faber, M., Wagenhals, G. (1993) Reducing $\mathrm{CO}_{2}$ emissions: A comparative InputOutput study for Germany and the UK. Springer-Verlag.

Robinson, H. D. (1988) Industrial pollution abatement: the impact on balance of trade. Canadian Journal of Economics 21, 187-199.

Rose, A., Casler, S. (1996) Input-Output structural decomposition analysis: a critical appraisal. Economic Systems Research 8 (1), 33-62.

Straumann, R. (2003) Exporting Pollution? Calculating the embodied emissions in trade for Norway. Report 2003/17, Statistics Norway.

Su, B., Huang, H. C., Ang, B. W., Zhou, P. (2010) Input-output analysis of $\mathrm{CO}_{2}$ emissions embodied in trade: The effects of sector aggregation. Energy Economics 32, 166-175.

Su, B., Ang, B.W. (2012) Structural decomposition analysis applied to energy and emissions: Some methodological developments. Energy Economics 34, 177-188. 
Su, B., Ang, B. W., (2013) Input-output analysis of $\mathrm{CO}_{2}$ emissions embodied in trade: Competitive versus non-competitive imports. Energy Policy 56, 83-87.

Su, B., Ang, B.W. (2014) Attribution of changes in the generalized Fisher index with application to embodied emission studies. Energy 69, 778-776.

Su, B., Ang, B.W. (2015) Multiplicative decomposition of aggregate carbon intensity change using input-output analysis. Applied Energy 154, 13-20.

Su, B., Ang, B.W. (2016) Multi-region comparisons of emission performance: The structural decomposition analysis approach. Ecological Indicators 67, 78-87.

Trefler, D., Zhu, S. C. (2010) The structure of factor content predictions. Journal of International Economics 82: 195-207.

Walter, I. (1973) The pollution content of American trade. Western Economic Journal 11, 61-70. WTO (2013) World Trade Report 2013 B. Trends in international trade. WTO, Geneva.

$\mathrm{Xu}, \mathrm{X}$. Y., Ang, B. W. (2013) Index decomposition analysis applied to $\mathrm{CO}_{2}$ emissions studies. Ecological Economics 93 (5), 313-329.

Zhang, H., Lahr, M. L. (2014) Can the carbonizing dragon be domesticated? Insights from a decomposition of energy consumption and intensity in China, 1987-2007. Economic Systems Research 26 (2), 119-140. 
